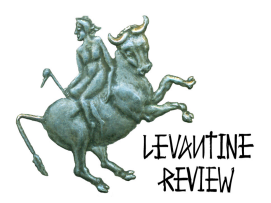

\title{
THE LEVANT: ZONE OF CULTURE OR CONFLICT?
}

\author{
Samir El-Youssef*
}

I didn't read Philip Larkin until the publication of his Selected Letters (19401985,) and the heated debate that they provoked. Larkin had been seen as one of the most beloved contemporary English poets, but in 1993, the year of the Letters' publication, it was revealed that in some of his private correspondence this great poet had expressed views that could only be deemed to be those of a racist. Some insisted that Larkin must be seen as the good poet he'd ever been. Others thought he should be dismissed. The intransigent question about Art and Politics had managed to make its way into the centre of attention again.

My first reading of Larkin was more like a detective mission; thorough text searching for clues, which could link his poetry to those few offending letters. Larkin's poems are riddled with signs of nostalgic yearning. In themselves such signs would have been deemed harmless were they not issuing from an English writer. In them were also hints of resentment towards anything modern or abroad. But there was no real evidence, no proof as it were, of a racist expression that could be used or brandished by way of indictment in any serious debate. My mission to impeach Larkin, I'm happy to report, was an absolute failure.

-Why happy?

-Happy because as I read Larkin's poems I came to enjoy quite a good number of them. Indeed I enjoyed more poems now than when reading many other poets whom I'd explored without the grudge of a detective-reader. Enjoying so many poems in such a small output made me come back to Larkin time and again, reading him with open mindedness and with no other purpose than the pleasure of reading poetry.

Repeated readings over the years made Larkin one of my most favourite poets. Still, racism is a serious matter, and when one's favourite poet is branded a racist, one must explain how it is possible to reconcile the irreconcilables. Some commentators and friends of the late poet tried the usual method of playing down the issue of racism. Some insisted that art and politics, especially politics expressed in private correspondence, are two separate realms that mustn't be confused. Others argued that those letters should only been seen within the historical and cultural context in which they were written. But none of these arguments holds water. Larkin is a bigot and there is no way of getting around this disgraceful fact. So how could one read him knowing what he is or what he was? 


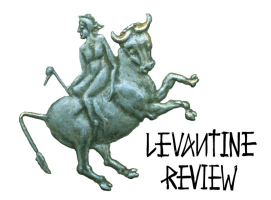

Larkin's poems are good, and like all good art they have the ability to make the audience forget the repugnant views of the artist and bypass his personality too. Reading Larkin poems, just like listening to Wagner music, one temporarily forgets what such artists might have said, in either the private or public spheres. The ability of art to induce temporary forgetfulness is what I would like to make use of in answering the question that is the title of this essay: "Is the Levant a zone of conflict or culture?"

When talking about the Levant, there are two important and closely connected issues one must keep in mind: memory and the attitude of each of the Levant's communities towards the "other."

Jews, Palestinians, Kurds and many other nations and minorities in the Middle East have had a past of grief and a history of suffering, and therefore memory is a very important and popular term in many Middle Eastern quarters. Indeed memory is so important that it seemed to be the major source of informing and goading a given community's political attitude towards the "other," and sometimes towards the "self." The trauma of the dark past is generated in deep fear and suspicion verging on paranoia. Accordingly the "other" is seen as someone who has no other wish and intention but that of defeating us, destroying us. Whatever statement and move the "other" makes is often seen as part of a wider, sophisticated, devious plot; an endless conspiracy within which whatever is prefigured years earlier is bound to take place. The "other's" group, the opposite group, is usually given too much credibility, suspected of being always cunning, skilfully organised and highly co-ordinated, or at least having the benefit of unshakable determination to keep on fighting to the end. Willingness to negotiate and reach a peace agreement is often viewed with suspicion that even those who participate seem to be expecting little besides their suspicions being confirmed and justified.

The protracted and farcical Palestinian-Israeli peace process is a good example of how such two aspects manifest themselves. In this context, any concession made, no matter how small and insignificant, is often considered the first of many other greater concessions to follow, leading eventually to the destruction of those surrendering to compromise. Indeed there were times when Palestinian and Israeli peace negotiators seemed to be waiting to see who is going to flinch first, who is going to fail to keep their part of the bargain. The desire to play the role of the tragic hero must have haunted the mind of those peace-makers and was ready to be animated on the world stage: "Look, we have tried everything to reach an agreement; we stretched our out hand to them but they turned it down!" I am sure that such attitudes and such discourse were rehearsed numerous times.

With such paranoia left unchallenged, no wonder peace remains illusive and very difficult, not to say impossible, to achieve. Reconciliation is doomed to remain a distant hope, so long as the "other" continues to be viewed with distrust. And so, 


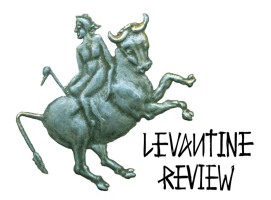

it seems that the common assumption that the Levant is evidently a zone of conflict, and worse, might remain so until doomsday, doesn't lack justification. But is there a way to challenge such a seemingly fated and enduring assumption?

Let us mention another term, which is just as popular as Memory: Resistance, or The Resistance. This is a sacred cow in many parts of the Levant. "No voice shall rise above the voice of the Resistance!" is an oft-repeated slogan. Once a group anoints itself a representative of the "resistance," or wraps itself in the mantle of some "resistance," any "resistance," it will have earned the right to do pretty much as it pleases - with impunity, as is often the case with many a "sacred" or "divine resistance" in the Levant today! So let us learn from the practitioners of "resistance" and establish our own resistance: The resistance against memory and paranoia. Indeed, what better way to resist unremitting "resistance" than to encourage forgetfulness?

But let me first emphasize two points: First, that the attitude of suspicion vis-àvis the "other" is peculiar to politics, or anything that is determined through politics. Secondly, that people are not necessarily enslaved to their dark memory. Indeed, whenever they can, they try to distract themselves from both memory and politics; the act of forgetfulness is not so strange to them. Indeed these two facts have encouraged me through the last two decades to challenge the assumption that the Levant is, or could only, be depicted as a zone of conflict. However, the temporary forgetfulness that I am talking about is not the same as seeking distraction from reality, or escaping reality, or being cynical.

Good art for me is that which combines pleasure with education, or simply an intelligent joke that makes one laugh and think and then laugh again. The chance to forget here is a chance to think, to discover something else, or something different, or at least to recognise the significance of something that one might have overlooked or dismissed. In other words, forgetfulness is a chance to unlearn an old lesson and learn a new one.

I enjoyed reading Larkin's poems, but I also learned a great deal from them; they taught me many things about the English language and post-war England, and how to distinguish between an attitude of disappointment and one of hostility, and between expressions of solidarity and appreciation, and hypocrisy and conceit. Within the Levant the moment of temporary forgetfulness might be a chance for learning how to pave the way for the imagination of peace.

People who followed the Peace Process through its visual aspect must have noticed how hesitant and reluctant participants in peace negotiations looked. Starting from the notorious Arafat-Rabin handshake on the White House lawn, peace negotiators looked as if they were doing a dirty job; something that they were undertaking out of sheer necessity and desperation. The private argument, which was often made, seemed to confirm the implication of the image on the White House lawn; "we have to be realistic-we can do nothing but negotiate 


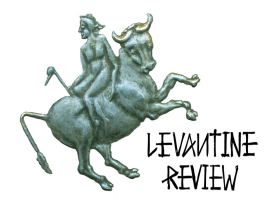

and reach a peaceful agreement." "Nothing" here means "we couldn't get rid of them or destroy them, so we have to make a deal with them."

No wonder the peace process has always looked like a half-baked process. When discussing what went wrong with the peace process an annoying expression was repeatedly used; "there is no culture of peace," it was often said. This makes one imagine communities in the Middle East doing nothing all day long except digging trenches.

That is not true! The Levant is no poorer a place than any other in the culture of peace. But what has been lacking in the Levant is actually the imagination of peace; people for a long time have been living in one state of conflict or another; or a state of no peace and no war, that they have no idea how the world might look like without war or the expectation of conflict and violence. Indeed people of the Levant seem to have got used to such assumptions that the alternative appears to them as an unreal world.

In a literary event that brought together a group of Palestinian and Israeli writers, just before the failure of Camp David Talks in 2000, I remember the late Israeli writer Batya Gur commencing her talk by reading Cavafy's famous poem Waiting for the Barbarians. There had been a moment of exaggerated hope at the time; a time during which a breakthrough in the Israeli-Syrian peace talks was expected. Such a breakthrough would have meant that the last major stumbling block before achieving total peace will have been surmounted. Yet, in spite of the exaggerated hope, as Gur explained, one could nevertheless still sense the feeling expressed in the last two lines of Cavafy's poem: "Now what will become of us without barbarians? / Those people were some kind of solution." Whenever there has been a breakthrough, the sense of "Now what will become of us without barbarian?" has spread. Why? Because imagination has failed to keep up with reality.

Imagination is meant to precede reality and to provide examples, models, and images of how the new reality, the world in a state of peace, would look like. Instead, when the time for peace arrived, imagination seemed to lag behind, stuck within an old world languishing in the tyranny of the memory of a dark past and an attitude of scepticism towards the "other." No wonder that every time a peace treaty has been signed, people felt that they were venturing into the wilderness or at least, like those who waited for the never-arriving barbarians, that they have been deprived from a source of consolation.

The question in the title of this essay, "is the Levant a zone of conflict or culture?" is an ironic one indeed. Anyone with a token knowledge of the Levant knows that the Levant is of both, conflict and culture; it is only that the people of the Levant need to be reminded that theirs is a land of great culture, and that they need pay more attention to it. I was born and brought up in Rashidiyyé-a Palestinian refugee camp in Southern Lebanon. Rashidiyyé was, and still is, as bad as a 


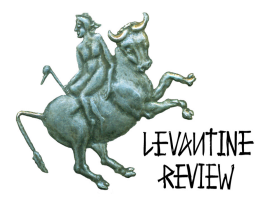

refugee camp could be. A mere fifteen minutes walk from the camp stood the ancient Phoenician port-city of Tyr; a harbour town housing the awesome vestiges of one of the greatest, most pacifist, most benevolent builders of civilization. The refugee camp (in its indigence,) and the ancient city (in all its glory,) standing side by side, is a stark example of the Levant being both a land of conflict and culture.

When Philip Larkin's offensive letters were published in 1993, some people suggested his poetry be struck off from school curricula. This reaction made me think back to the old school of my boyhood, back in the Rashidiyyé refugee camp. Our teachers then talked up a storm about politics, the conflict, the hopelessness and indigence of our situation. Yet I don't remember any of them suggesting a school tour to the nearby Phoenician port-city of Tyre, a living testament as it were, to the ancient Levant; a place where we could, even for a fleeting moment, forget the misery of our present days and learn something new, something different, something hopeful; learn how when looking at what lay outside the "prison walls," and when considering that which challenges prevalent assumptions, one might be able to see above the clouds of past traumas, and beyond the paranoia of present days.

* Samir El-Youssef is a London-based Palestinian novelist. He is the author of several books and novellas, including Illusion of Return and a collection of shortstories, Gaza Blues, co-authored with Israeli novelist Etgar Keret. An essayist and public intellectual, El-Youssef has contributed to various publications in Europe and the Middle East, and was recipient of the 2005 PEN Tucholsky Award in recognition of his commitment to the promotion of peace and freedom of speech in the Middle East. This essay is an adaptation of a November 2012 talk that ElYoussef delivered at Boston College, under the auspices of the Heinz Bluhm Memorial Lectures Series in European Literature. 